\title{
EQUIDADE INTERGERACIONAL: SUSTENTABILIDADE AMBIENTAL PARA GERAÇÕES VINDOURAS
}

Keit Diogo Gomes ${ }^{1}$

RESUMO: Esta pesquisa propõe-se a verificar as futuras gerações como titulares de direitos, com o escopo de que lhe sejam assegurados o cesso a sustentabilidade ambiental. A abordagem aqui proposta adota o método qualitativo-dedutivo e objetiva propor estratégias que possam ser empregadas para o alcance da equidade intergeracional no contexto global. $O$ trabalho desdobra-se em três partes. Na primeira, será analisado quem são as futuras gerações; na segunda, será estudada especificamente a teoria da equidade intergeracional. Por fim, serão apresentadas algumas opções a serem implementadas em nível global e local, para a garantia da sustentabilidade ambiental no por vir.

PALAVRAS-CHAVE: Sustentabilidade; Equidade; Intergeracional; Global; Gerações.

\section{INTERGERATIONAL EQUITY: ENVIRONMENTAL SUSTAINABILITY FOR VINDOR GENERATIONS}

\begin{abstract}
This research proposes to verify the future generations as right holders, with the scope that they are guaranteed the environmental sustainability. The approach proposed here adopts the qualitative-deductive method and aims to propose strategies that can be used to achieve intergenerational equity in the global context. The work unfolds in three parts. In the first, it will be analyzed who the future generations are; in the second, the theory of intergenerational equity will be specifically studied. Finally, some options will be presented to be implemented at a global and local level, to guarantee environmental sustainability in the future.
\end{abstract}

KEYWORDS: Sustainability; Equity; Intergenerational; Global; Generations.

\footnotetext{
${ }^{1}$ Professora na Universidade Federal de Mato Grosso e advogada. Mestra em Direito Agroambiental e especialista em Direito Penal e Processual Penal.
}

Rev. de Direito e Sustentabilidade | e-ISSN: 2525-9687 | Porto Alegre | v. 4 | n. 2 | p. 1-19 | Jul/Dez. 2018 


\section{INTRODUÇÃO}

A compreensão de que as futuras gerações estão diretamente ligadas às gerações passadas e atuais, é relevante para compreender que a raça humana está umbilicalmente conectada entre passado, presente e futuro. Não é possível desvincular esta interdependência. Afinal, as gerações atuais somente podem viver em virtude do que foi realizado e mantido por meio das anteriores, e consequentemente, as futuras gerações, dependem de preservação dos recursos ambientais atuais para que possam sobreviver e dar continuidade à raça humana.

Eis aqui a relevância do tema, pois a busca de sustentabilidade ambiental para as futuras gerações é uma medida a ser tomada na contemporaneidade, sob pena de esgotamento dos recursos ambientais indispensáveis para a qualidade de vida das gerações que ainda estão por vir. Compreender que o acesso ao meio ambiente equilibrado não se restringe as sociedades hodiernas, mas deve ser vista como imperativo para todas aquelas que venham a povoar o planeta, implica em reconhecer a existência dos direitos intergeracionais.

O objetivo deste estudo concentra-se em identificar caminhos viáveis à promoção da equidade intergeracional, para a efetivação de sustentabilidade ambiental em nível global para as futuras gerações. Algumas alternativas mostram-se como caminhos a serem perquiridos para a efetivação desta proposta, destacando-se alguns deles, tais como a adoção de uma governança ambiental em níveis locais e internacionais; uma mudança de paradigma consistente na consolidação de uma ética ambiental; e a adoção de mecanismos nas esferas nacionais e internacionais, aptos a fomentar a busca pela proteção dos direitos ambientais das gerações vindouras.

Uma problemática central deve nortear a evolução da pesquisa, o que se verifica através das seguintes questões: os esforços empreendidos na seara ambiental nacional e internacional são suficientes a garantir a manutenção do meio ambiente em favor das gerações que habitarão o planeta nas próximas décadas ou séculos? As gerações futuras, aquelas com existência incerta, mas com expectativa de que venham a existir, são merecedoras de proteção jurídica-ambiental?

Esta pesquisa foi pautada pela adoção do método bibliográfico, valendo-se de uma abordagem qualitativa e dedutiva de análise de dados. O texto foi estruturado em três capítulos, nos quais serão abordados, respectivamente: quem são as futuras gerações; a teoria da equidade intergeracional, e por derradeiro, alternativas para a implementação de uma sustentabilidade ambiental intergeracional. 


\section{QUEM SÃO AS FUTURAS GERAÇÕES?}

O principal objeto da teoria da equidade intergeracional destina-se a proteção das gerações que ainda estão por vir logo, é pertinente identificar quem são essas gerações que serão protegidas pela equidade intergeracional. De modo preliminar, é necessário dizer que não existe unanimidade sobre este conceito, recorrendo-se, portanto, a variadas contribuições já formuladas.

Um dos principais enfoques para se determinar quem são as futuras gerações consiste no critério temporal, denominado como transtemporal cross-temporal argument, que concebe a sociedade humana como uma corrente, onde cada geração corresponde a um elo. (BRANDÃO \& SOUZA, 2010, p. 167/168). Eis a seguir um conceito de geração fulcrado no quesito temporal, formulado por Hirdan Costa:

Assim, o ponto de partida para a justiça intergeracional é definir o conceito de geração e o lapso temporal de cada geração. Por "geração" entende-se o conjunto de pessoas nascidas no mesmo período histórico, que recebem, assim, os mesmos estímulos socioculturais. Comte (1998) apresenta uma visão quantitativa e matemática do tempo das gerações, 30 anos, calculado a partir do período em média que uma geração seja substituída por outra na vida pública. (MENDES, 2016, p.20)

O lapso temporal, como fator de caracterização das gerações, é um critério que tem sido debatido por diversos autores. Enquanto alguns ainda seguem o modelo inicial, apontando como marco temporal o critério de 30 anos, outros já se dispõe a discutir gerações baseadas em 50 anos ou mais, tendo em vista a crescente expectativa de vida, que tem se expandido ao redor do globo.

\footnotetext{
Com relação aos direitos das gerações futuras, não existe certamente nenhuma implicação de que, quando uma nova geração surgir, a existente deva desaparecer. De qualquer modo, além dos problemas de terminologia, o conceito de geração é obscuro. Historicamente, considerando a variada expectativa de vida no passado, a duração de uma geração foi aceita como sendo de trinta anos. A relevância de tais estimativas, em vista de uma maior expectativa de vida no mundo desenvolvido e as grandes diferenças entre países desenvolvidos e países em desenvolvimento, é altamente questionável. (KISS, 2004, p.15)
}

Discordando de um conceito estanque de geração e sua determinação temporal, Alexandre Kiss destaca, então, uma terminologia própria que acaba por ser encampada por outros autores com o fim de evitar a dubiedade decorrente do quesito temporal. O autor desenvolve o termo "fluxo constante", no qual as diversas gerações convivem de forma intercalada, tendo em vista que crianças, jovens, adultos e idosos estão sempre a se relacionar em um mesmo período temporal. 
De forma conceitual, o principal problema é que não há nenhuma geração distinta. Em cada duas centenas de seres humanos que nascem e morrem, mais de cinco bilhões de pessoas de todas as idades coexistem. Seria mais exato falar não de gerações, mas de um fluxo constante; a humanidade pode ser comparada a um enorme rio que flui constantemente, torna-se cada vez maior e nele nenhuma distinção pode ser feita entre as gotas de água que formam esse rio. (KISS, 2004, p.15)

Compreender quem são as futuras gerações impõe o dever de aceitar o elo existente entre as gerações passadas e atuais, dando continuidade a existência. É necessário compreender que as sociedades passadas fizeram sacrifícios para as atuais e igualmente as gerações atuais, em uma concepção de proteção, tem o dever de salvaguardar os bens ambientais para as próximas gerações. Isto implica reconhecer que a espécie humana não pode viver de forma isolada e desconexa com sua história remota e com sua perspectiva de futuro, sob pena de extinguir os recursos ambientais e até a própria extinção da raça humana. (BRANDÃO \& SOUZA, 2010, p. 167/168).

Para o fim de estabelecer um contraponto, há que se mencionar, ainda, uma visão diferenciada, proposta por Hirdan Costa, ao dialogar que sequer se mostra pertinente distinguir gerações atuais das que estão por vir, tendo em vista a continuidade da vida planetária.

\footnotetext{
Sendo assim, qual o sentido de se separar os indivíduos entre os das gerações atuais e os que pertencerão a gerações futuras? Do ponto de vista epistemológico, não faz sentido, porque, considerando a continuidade da vida na no globo terrestre, os seres humanos são únicos e totalmente co-responsáveis por suas criações, independentemente do conceito de gerações. (COSTA, 2012, p. 39)
}

Como observado, não é possível determinar com precisão quem são as futuras gerações. Todavia, independentemente da adoção do critério temporal, ou ainda, sob a perspectiva de fluxo constante proposta por Alexandre Kiss, um consenso é verificável, a necessidade de que estas gerações que estão por vir devem ser protegidas, razão pela qual recursos ambientais devem ser resguardados para que possam ser usufruídos por aqueles que ainda não são nascidos. Este é o entendimento encampado por alguns dos principais autores sobre o tema, ao qual este trabalho se perfilha.

\section{A TEORIA DA EQUIDADE INTERGERACIONAL}

A equidade é uma terminologia costumeira a ciência jurídica, empregada em diversos ordenamentos jurídicos em todo o mundo, estando atrelada ao sentimento de igualdade, justiça, distribuição proporcional de bens. Há autores que afirmam que a equidade está vinculada aos postulados da Revolução Francesa, expressos por meio da tríade: liberdade, igualdade e 
fraternidade, sendo esta última o fundamento para a proteção das gerações futuras. (SILVA, 2011, p.123).

Alguns juristas atribuem uma ligação entre a equidade e a concepção primitiva de justiça, focada nos primórdios do Direito Natural. Com suporte nesta perspectiva, ao se aplicar a equidade entre as partes envolvidas em determinada lide, busca-se a aplicação mais próxima da justiça para ambos os envolvidos, sem descurar-se da aplicação da lei. Este é o caminho apontado por Sérgio Sampaio Figueira (2010, p.3):

\begin{abstract}
O termo equidade advém do latim aequitas, aequitatis, que, na Língua Portuguesa, apresenta-se como substantivo feminino, significando: justiça natural, igualdade, justiça, retidão. A equidade é convencionada como regra aplicada a um caso específico, deixando-a mais justa e mais humana possível, denotando, ao mesmo tempo, preocupação com a aplicação da lei e com o formato mais próximo possível do justo para as partes envolvidas, estando, tradicionalmente, a equidade ligada ao Direito Natural.
\end{abstract}

A proposta da equidade intergeracional está direcionada àquelas gerações humanas que ainda não existem, abarcadas por uma expectativa de vida. Proteger esta categoria de indivíduos pressupõe que, daqui a cinquenta ou cem anos, os próximos habitantes possam desfrutar e usufruir dos recursos naturais atualmente existentes. A teoria desenvolvida é inovadora, porquanto, pretende preservas espécies animais e vegetais, bem como a qualidade do ar, água e recursos terrestres para que as próximas gerações possam conhecê-las e gozá-las, tais como estão disponíveis em nossos dias atuais, estando as futuras gerações reconhecidas como sujeitos de direitos (KISS, 2004, p. 54/55).

A equidade intergeracional cuida-se de uma teoria incorporada em diversos instrumentos legais em todo o mundo, visando promover a igualdade de acesso aos recursos naturais às gerações vindouras. Esta teoria parte da concepção de que as atuais gerações que habitam o planeta terra, não estão em nível hierárquico superior aos habitantes ainda não nascidos, cabendo, portanto, o dever de uso racional e sustentável dos recursos ambientais, de maneira a garantir a sua existência às futuras gerações.

Edith B. Weiss é uma das precursoras a defender a teoria da equidade intergeracional, tendo escrito diversos estudos para a apresentação da teoria e propostas de sua implementação em diversos níveis. A teoria da equidade proposta pela autora sustenta-se, sobretudo, em dois níveis; a forma como a presente geração se relaciona com as demais gerações e, ainda, a forma como a geração presente se relaciona com o meio ambiente, no qual está inserida. Ela ressalta a importância da 
espécie humana assumir a responsabilidade de cuidar do planeta, uma vez que somos os seres vivos mais sensíveis:

There are two relationships that must shape any theory of intergenerational equity in the context of our natural environment: our relationship to other generations of our own species and our relationship to the natural system of which we are a part. The human species is integrally linked with other parts of the natural system; we affect and are affected by what happens in the system. We alone among all living creatures have the capacity to shape significantly our relationship to the environment. We can use it on a sustainable basis or we can degrade environmental quality and deplete the natural-resource base. As the most sentient of living creatures, we have a special responsibility to care for the planet $^{2}$. (WEISS a, 1992, não paginado)

A formulação da autora assenta-se no fato de que todas as gerações são corresponsáveis pela manutenção dos recursos naturais, portanto, as gerações passadas, as atuais e as que estão por vir, nada mais são do que beneficiárias dos recursos ambientais. Deste modo, não se concebe a existência de hierarquia ou qualquer prevalência entre uma geração e outra, tendo em vista que todas estão no mesmo patamar para utilizar dos recursos naturais disponíveis, não havendo nenhuma base para que a geração futura tenha privilégios em seu uso do planeta:

The second fundamental relationship is that between different generations of the human species. All generations are inherently linked to other generations, past and future, in using the common patrimony of earth. The theory of intergenerational equity stipulates that all generations have an equal place in relation to the natural system. There is no basis for preferring the present generation over future generations in their use of the planet $^{3}$. (WEISS b, 1992, não paginado)

Estando estabelecido que as gerações que habitam, habitaram ou habitarão o planeta são corresponsáveis pela manutenção do meio ambiente, cabe, portanto, o dever das gerações contemporâneas manter o padrão de disponibilidade de recursos para as gerações vindouras. Caso haja falhas nesta conservação, as gerações por vir têm o dever de reparar o

\footnotetext{
2 Tradução: [Há duas relações que devem moldar qualquer teoria da equidade intergeracional no contexto de nosso ambiente natural: a nossa relação com outras gerações de nossa própria espécie e nossa relação com o sistema natural do qual fazemos parte. A espécie humana está integralmente ligada com outras partes do sistema natural; que afetam e são afetados pelo que acontece no sistema. Somente nós entre todos os seres vivos temos a capacidade de moldar significativamente a nossa relação com o meio ambiente. Podemos usá-lo em uma base sustentável ou podemos degradar a qualidade ambiental e esgotar a base de recursos naturais. Como o mais sensível dos seres vivos, temos uma responsabilidade especial de cuidar do planeta].

3 Tradução [A segunda relação fundamental é que entre as diferentes gerações da espécie humana. Todas as gerações são interligadas a outras gerações, passado e futuro, no uso do patrimônio comum da terra. A teoria da equidade intergeracional estipula que todas as gerações têm um lugar igual em relação ao meio ambiente. Não há nenhuma base para preferir a atual geração ao longo de gerações futuras em seu uso do planeta].
}

Rev. de Direito e Sustentabilidade | e-ISSN: 2525-9687 | Porto Alegre | v. 4 | n. 2 | p. 1 -19 | Jul/Dez. 2018 
dano, podendo utilizar-se, para isto, de rendas provenientes de seus antepassados e demais conhecimentos que lhes foram proporcionados por avanços tecnológicos, por exemplo. Ainda que para isto, a restauração tenha que ocorrer de forma gradativa.

A autora ainda salienta que, por questões culturais e religiosas, a maioria dos povos consegue conceber a visão de que são usufrutuários do planeta, reconhecendo que estão apenas de passagem pela vida na Terra, com o direito de nos beneficiarmos do planeta para nós mesmos, mas também de cuidar dela para nossos descendentes:

\begin{abstract}
Fortunately, the notion that each generation holds the earth as a trustee or steward for its descendants strikes a deep chord with all cultures, religions and nationalities. Nearly all human traditions recognize that we, the living are, sojourners on earth and temporary stewards of our resources. The theory of intergenerational equity states that we, the human species, hold the natural environment of our planet in common with other species, other people, and with past, present and future generations. As members of the present generation, we are both trustees, responsible for the robustness and integrity of our planet, and beneficiaries, with the right to use and benefit from it for ourselves ${ }^{4}$. (WEISS b, 1992, não paginado)
\end{abstract}

Com esteio nesta concepção, não se verifica a existência de conflitos entre a configuração da equidade intrageracional face à equidade intergeracional. Para a autora, a formatação de ambos os postulados de equidade, devem caminhar em conjunto de forma coerente. Enquanto as gerações contemporâneas possuem o direito de usufruir e aproveitar os recursos naturais, as demais gerações, amparadas pela igualdade, possuem o mesmo direito de forma subjacente.

Com a finalidade de implementar a equidade intergeracional, Edith B. Weiss sustenta que os direitos e obrigações entre as gerações devem ser avaliados em dois patamares. $\mathrm{O}$ primeiro deles, consistente em ações gerais e o segundo, em ações específicas. Todavia, a principal estratégia determinada pela citada autora, consiste em dar o direito de representação as futuras gerações.

Essa representação tomaria forma de diversas maneiras, tais como na tomada de decisões na esfera administrativa, judicial e também por meio de decisões sobre o mercado. A

\footnotetext{
4 Tradução livre: [Felizmente, a noção de que cada geração detém a terra como um fiduciário ou administrador para os seus descendentes golpeia uma corda profunda em todas as culturas, religiões e nacionalidades. Quase todas as tradições humanas reconhecem que nós, os vivos somos peregrinos na terra e administradores temporários de nossos recursos. A teoria da equidade intergeracional afirma que nós, a espécie humana, deve manter o ambiente natural do nosso planeta em comum com outras espécies, outras pessoas, e com o passado, presente e futuras gerações. Como membros da geração atual, nós somos os curadores responsáveis pela robustez e integridade do nosso planeta, e os beneficiários, com o direito de usar e se beneficiar dele para nós mesmos].
} 
nomeação de um escritório mantido por recursos públicos seria responsável por assegurar a representação das gerações por vir. A comissão poderia, ainda, tomar para si as atribuições de assegurar o cumprimento das leis ambientais, apurar denúncias de ilegalidades e informar a população sobre outros problemas. Verifica-se que a teoria de equidade intergeracional, formulada por Edith B. Weiss, é bastante completa.

A autora expõe seus fundamentos e ainda apresenta alternativas a serem consideradas para sua efetiva implementação. Enfrenta algumas das principais críticas que lhe são dirigidas, concernentes a inviabilidade de se concretizar a equidade intrageracional e intergeracional, bem como o paradoxo da titularidade de direitos para as futuras gerações. Este último enfrentamento será objeto de tópico específico neste trabalho, motivo pelo qual os argumentos da autora serão reservados para serem empregados no momento apropriado.

\subsection{Modelos Alternativos à Teoria da Equidade Intergeracional}

Existem abordagens alternativas para tratar a utilização dos recursos naturais pelas gerações atuais e futuras, e é exatamente para enfrentar cada um destes modelos e demonstrar que eles não atendem aos interesses coletivos que Edith Brown Weiss formula sua teoria de equidade intergeracional. Estes arquétipos apresentam saídas variadas para lidar com o esgotamento dos recursos ambientais. Os modelos, a seguir delineados, são assim denominados: modelo preservacionista, modelo da opulência e modelo da economia ambiental.

\subsubsection{Modelo preservacionista}

O modelo preservacionista fundamenta-se na premissa de que as gerações contemporâneas têm o dever de não destruir ou tampouco esgotar os recursos ambientais disponíveis. Antes pelo contrário, tem o dever de economizar os recursos existentes para que possam oferecê-los em iguais condições às gerações vindouras.

The first is the preservationist model, in which the present generation does not destory or deplete resources or significantly alter anything; rather it saves resources for future generations and preserves the same level of quality in all aspects of the environment. This preservationist model has deep roots in the original natural-flow theory of English water law, in which riparians could use stream water so long as their use did not impair in any way the quantity or quality of water for those downstream. Ultimately this benefits the last riparians before the stream enters the ocean or 
disappears, because they have no one to whom they owe an obligation ${ }^{5}$. (WEISS a, 1992, p. 5)

O modelo preservacionista tende a uma abordagem radical, sendo alvo de severas críticas, uma vez que a obrigatoriedade de manter o status quo do meio ambiental é tarefa impossível. O dever de preservação sustenta-se em uma premissa correta, todavia, a limitação de utilização de recursos visando a criação de uma poupança ambiental para as futuras gerações, acabaria por limitar aquelas que ainda não dispõe das condições mínimas para o seu usufruto nas sociedades atuais.

\subsubsection{Modelo da opulência}

Outro modelo de caráter extremado, o modelo da opulência, prega exatamente o oposto do modelo preservacionista. Este parâmetro transmite a ideia de que não há que se preocupar com gerações futuras, pois sequer é possível saber se elas de fato irão existir. Logo, os indivíduos devem consumir os recursos ambientais da forma que lhes for mais conveniente.

The other extreme can be termed the opulence model' in which the present generation consumes all that it wants today and generates as much wealth as it can, either because there is no certainty that future generations will exist or because maximizing consumption today is the best way to maximize wealth for future generations ${ }^{6}$. (WEISS a, 1992, p. 6)

O modelo da opulência não exclui a possibilidade de existência das futuras gerações. Todavia, não sustenta a ideia de sua proteção, considerando que não seria possível determinar a sua ocorrência. O modelo da opulência apresenta ainda uma variante, consistente no modelo da tecnologia. (WEISS a, 1992, p.6). Este arquétipo alude que a inovação tecnológica produzida será suficiente para produzir eventuais substitutos ambientais para as próximas gerações.

\footnotetext{
${ }^{5}$ Tradução livre: [O primeiro é o modelo preservacionista, em que a geração atual não destrua ou esgote os recursos ou altere significativamente nada; em vez disso, economiza recursos para as gerações futuras e preserva o mesmo nível de qualidade em todos os aspectos do ambiente. Este modelo preservacionista tem raízes profundas na teoriafluxo natural original da lei da água Inglês, no qual ribeirinhos poderia usar água do córrego, desde que a sua utilização não prejudicou de forma alguma a quantidade ou a qualidade da água para aqueles a jusante. Em última análise, isso beneficia os últimos ribeirinhos diante do rio entra no mar ou desaparece, porque eles não têm ninguém a quem devem uma obrigação].

${ }^{6} \mathrm{O}$ outro extremo pode ser denominado o modelo opulência, em que a geração atual consome tudo o que ele quer hoje e gera tanta riqueza quanto possível, seja porque não há certeza de que as futuras gerações existem ou porque maximizando o consumo de hoje é a melhor maneira para maximizar a riqueza para as gerações futuras. (Weiss, 1992, p. 6)
} 
A variant of the opulence model is the technology model, in which we do not need to be concerned about the environment for future generations, because technological innovation will enable us to introduce infinite resource substitution. While technology will undoubtedly enable us to develop some substitutes for certain resources and to use resources more efficiently, it is by no means assured that it will suffice or will make the robustness of the planet irrelevant ${ }^{7}$. (WEISS a, 1992, p. 6)

Este modelo pode ser alvo de críticas em larga escala. Basta verificar se as gerações passadas houvessem utilizado os recursos ambientais sem qualquer espécie de controle, diversas espécies de plantas e animais já estariam extintas do planeta, isto sem mencionar o exaurimento dos recursos minerais. Melhor sorte não assiste ao modelo da tecnologia, uma vez que não é possível prever em que medida o conhecimento tecnológico se tornará autossuficiente para suprir as demandas ambientais da humanidade.

Para exemplificar essa situação, basta aludir-se ao avanço na área das ciências médicas e da saúde. Ainda que diversas substâncias tenham sido descobertas e testadas nos últimos anos, o processo de sua implementação é moroso e carece de uma série de experimentos que lhe tornem confiáveis para utilização. Mesmo com os avanços já perpetrados, são inúmeras as moléstias que seguem sem opções de cura.

O modelo da opulência não observa a disparidade social existente entre os membros da mesma coletividade. Se alguns membros possuem condições de acesso aos recursos, ou recursos financeiros suficientes para deles adquirir e usufruir de forma exacerbada, outras parcelas pobres continuarão a não se beneficiar deste modelo, pela carência de recursos financeiros que lhes inviabiliza acessar os recursos ambientais.

\subsubsection{Modelo de economia ambiental}

O modelo da economia ambiental é sem dúvidas o que mais tem conquistado filiados. $\mathrm{Na}$ atualidade, o modelo da economia ambiental tem sido amplamente divulgado e propagado por empresas privadas e, em alguns casos, incentivada pelo poder público em variados países. Este sistema preconiza uma concepção econômica, onde acredita-se que as ferramentas desenvolvidas pelo mercado, aliada a proposta de uma "economia verde" são mecanismos suficientes para garantir a preservação de recursos para as futuras gerações.

\footnotetext{
${ }^{7}$ Uma variante do modelo de opulência é o modelo de tecnologia, em que não precisa se preocupar com o meio ambiente para as gerações futuras, porque a inovação tecnológica irá permitir-nos introduzir infinitos recursos substitutos. Embora a tecnologia, sem dúvida, nos permitirá desenvolver alguns substitutos para certos recursos e utilizar os recursos de forma mais eficiente, é de maneira nenhuma certeza de que ele será suficiente ou vai fazer a robustez do planeta irrelevante. (Weiss, 1992, p. 6)
}

Rev. de Direito e Sustentabilidade | e-ISSN: 2525-9687 | Porto Alegre | v. 4 | n. 2 | p. 1 - 19 | Jul/Dez. 2018 
Finally, we have the environmental economics model, which argues that if were to do proper natural resource accounting, we would fulfil our obligations to future generations. The economic tools that we have developed today -environmental externalities and discounting- are sufficient, were we to apply "green" economics. While proper accounting is essential to implementing intergenerational equity, it arguably is not sufficient as presently conceived ${ }^{8}$. (WEISS b, 1992, p. 6)

O modelo da economia ambiental reconhece a necessidade de uma proteção ambiental voltada as gerações por vir. Todavia, este modelo acredita que os mecanismos de mercado já impregnados são suficientes para garantir a proteção intergeracional necessária. Essa concepção é no mínimo simplista. A introdução do conceito de economia verde, tende a criar uma falsa percepção de proteção ambiental, quando na verdade, esta bandeira verde tem sido encampada por diversas empresas ou conglomerados que pouco ou nada se preocupam com a causa ambiental, mas que se utilizam destes mecanismos como formas de marketing.

Variados estudos demonstram que os recursos ambientais estão em franco declínio, sendo certo que a humanidade já esgotou os recursos atuais disponíveis, criando apenas um passivo ambiental. Logo, conceber que as ferramentas de mercado formatadas com interesse primordial em atender aos parâmetros econômicos, serão suficientes a suprir a demanda ambiental, faz crer um mínimo de ingenuidade.

Considerando a existência dos modelos até aqui relatados, o modelo preservacionista, modelo da opulência com a variante do modelo da tecnologia e ainda o modelo da economia ambiental, é possível verificar que a teoria proposta por Edith Brown Weiss chega mais próximo de atender a proteção ambiental sob a vertente das futuras gerações. Ainda que a teoria proposta possa ser influenciada por críticas, o seu aperfeiçoamento é possível, visando o melhor atendimento das gerações contemporâneas e futuras, com fins de melhor adequar a utilização dos recursos ambientais ao usufruto das gerações atuais, mas também com foco de garantir o seu uso e disponibilidade às gerações vindouras.

\section{AS FUTURAS GERAÇÕES ENQUANTO TITULARES DE DIREITOS?}

A ciência jurídica tem enfrentado dificuldades em adequar a proteção das futuras gerações, tendo em vista que estas categorias de indivíduos escapam as técnicas jurídicas

\footnotetext{
${ }^{8}$ Tradução livre [Finalmente, temos o modelo de economia ambiental, que argumenta que se fôssemos fazer contabilidade adequada de recursos naturais, cumpriríamos nossas obrigações para com as gerações futuras. As ferramentas econômicas que desenvolvemos hoje - externalidades ambientais e descontos - são suficientes para aplicar a economia "verde". Embora a contabilidade apropriada seja essencial para implementar a equidade intergeracional, não é discutivelmente suficiente]. (Weiss, 1992, p. 6)
}

Rev. de Direito e Sustentabilidade | e-ISSN: 2525-9687 | Porto Alegre | v. 4 | n. 2 | p. 1 - 19 | Jul/Dez. 2018 
empregadas tradicionalmente, tais como: teoria do nascituro, representatividade, titularidade de direitos e distribuição de deveres. A existência de um grupo indeterminado de indivíduos a quem não se pode garantir existência, mas que ainda sim, recebe tratamento legal, suscita embates.

Falar em futuras gerações, sobre pessoas indeterminadas, que não estão aqui ainda e não se sabe quando estarão, suscita uma série de problemas, principalmente quando se adentra o campo do Direito, por natureza pragmático e imediatista. Como conferir direitos a quem não tem existência nem representação? E por que razão a humanidade, também pragmática e imediatista, se preocuparia em assegurar tais direitos? (BRANDÃO \& SOUZA, 2010, p. 167)

E ainda:

Hoje, porém, o problema que tange especificamente à dimensão jurídica é a relacionada à representação das futuras gerações. Isso ainda é alvo de polêmica, como representar quem ainda não nasceu? A teoria dos direitos do nascituro é insuficiente para tal questão. As gerações futuras não são efetivamente representadas no processo de tomada de decisão hoje, embora tais decisões afetem o futuro. Isso requer que se entenda o direito fundamental entre as gerações corretamente, para que se reconheça que as gerações futuras têm uma reivindicação de igualdade com a geração atual. (BOLSON, 2012, p. 232)

Uma das principais dificuldades a ser superada para a caracterização da equidade intergeracional, está relacionada ao reconhecimento das gerações vindouras enquanto titulares de direitos. Reconhecer esta responsabilidade com os que estão por vir não torna a tarefa simples dentro da ótica jurídica. A Assembleia Geral das Nações Unidas, de outubro de 2013, enfrentou a temática, apontando o seguinte questionamento:

Future persons as holders of rights?

19. Even though intuitively many people may agree that present generations have obligations and duties to future generations, in moral and legal terms it is hard to assign moral significance to non-existing beings. Simply put, it is argued that future persons cannot have rights because they do not yet exist - they cannot possess anything, including rights. In legal terms, it is argued that rights go hand-in-hand with duties; legal duties cannot exist absent legal rights, so that present generations cannot have legal obligations to future generations. If the rights-holder does not exist, it is difficult to conceive of anyone being under a corresponding duty ${ }^{9}$. (UNITED NATIONS, 2013, p. 14)

\footnotetext{
${ }^{9}$ Tradução: [Futuras pessoas como titulares de direitos? 19. Mesmo que intuitivamente muitas pessoas podem concordar que as gerações presentes têm obrigações e deveres para com as gerações futuras, em termos morais e legais é difícil atribuir significado moral para seres não-existentes. Simplificando, argumenta-se que pessoas futuras não podem ter direitos, porque eles ainda não existem - eles não podem possuir qualquer coisa, incluindo direitos. Em termos legais, argumenta-se que os direitos andam lado-a-lado com os deveres; deveres legais não podem existir direitos legais ausentes, para que as gerações presentes não podem ter obrigações legais para com as gerações futuras. Se o titular do direito não existe, é difícil conceber que alguém estar sob um dever correspondente].
}

Rev. de Direito e Sustentabilidade | e-ISSN: 2525-9687 | Porto Alegre | v. 4 | n. 2 | p. 1 - 19 | Jul/Dez. 2018 
Edith Brown Weiss, principal precursora da teoria da equidade intergeracional também enfrenta o que denomina de paradoxo da titularidade de direitos para as futuras gerações. A autora argumenta que a dificuldade enfrentada reside no fato de querer-se delinear os direitos das gerações vindouras, nas categorias de direitos individuais identificáveis. Eis a seguir, o questionamento apontado pela autora.

It has been argued that future generations cannot have rights, because rights exist only when there are identifiable interests, which can only happen if we can identify the individuals who have interests to protect. Since we cannot know who the individuals in the future will be, it is not possible for future generations to have rights ${ }^{10}$. (WEISS b, 1992, p. 14)

Para Edith Brown Weiss, os direitos intergeracionais não se assentam no âmbito dos direitos individuais, mas devem ser concebidos como direitos planetários, que devem ser analisados sob o contexto temporal. Tais direitos devem ser vistos como grupos, em relação aos demais direitos das outras gerações, sejam elas passadas, presentes ou futuras. Outro enfrentamento realizado pela autora, consiste na máxima de que, para cada direito, deve corresponder uma obrigação. Assevera a autora que esta premissa não se mostra verdadeira. Embora para os direitos estejam naturalmente vinculados a obrigações, nem todas as obrigações pressupõe a existência de um direito.

One might still ask whether it is not preferable to speak only of planetary obligations toward future generations without corresponding intergenerational rights. Can intergenerational obligations exist without rights? While rights are always connected to obligations, the reverse is not always true. Theoretically, an obligation need not always entail a right. For example, a moral obligation of charity does not give those who benefit a right to charity ${ }^{11}$. (WEISS, 1992, p. 14)

A superação destas antinomias deve encontrar respaldo na própria ciência jurídica, por meio da utilização de institutos jurídicos já existente ou da criação de novos, que visem suprir as contradições que possam se manifestar. Lara França Mendes (2016, p.65) apresenta, como resposta, a possibilidade de que as futuras gerações sejam tratadas como entidades sem personalidade jurídica, mas que sejam titulares de direitos.

\footnotetext{
10 Tradução livre: [Tem sido argumentado que as gerações futuras não pode ter direitos, porque existem direitos somente quando há interesses identificáveis, o que só pode acontecer se nós podemos identificar os indivíduos que têm interesses a proteger. Como não podemos saber quem são os indivíduos no futuro será, não é possível para as futuras gerações a ter direitos.]

${ }^{11}$ Tradução: [Pode-se ainda perguntar se não é preferível a falar apenas de obrigações para com as futuras gerações planetárias sem correspondente direito das novas gerações. Pode obrigações intergeracionais existir sem direitos? Embora os direitos estão sempre conectados às obrigações, o contrário nem sempre é verdade. Teoricamente, uma obrigação não precisa sempre implicam um direito. Por exemplo, uma obrigação moral da caridade não dá aqueles que se beneficiam de um direito de caridade].
}

Rev. de Direito e Sustentabilidade | e-ISSN: 2525-9687 | Porto Alegre | v. 4 | n. 2 | p. 1 - 19 | Jul/Dez. 2018 
Resposta bastante interessante é apresentada por Luis Ortega e Jesús Ortega ao afirmar que os direitos intergeracionais não podem ser visto sob a lente tradicional do direito civilista. Há que se considerar que os direitos intergeracionais não são individuais, segundo os autores, logo, se for adotada a teoria da equidade intergeracional, tais direitos não podem ser tratados dentro das categorias de direitos pessoais ou reais.

Nuestro punto de partida es la siguiente constatación: Los Estados pueden crear derechos y obligaciones conforme al principio de pacta sunt servanda. Al evidenciarse que la responsabilidad hacia las generaciones futuras se repite en diversos tratados internacionales, se estaría em condiciones de afirmar que los Estados-parte han decidido observar uma conducta de respeto hacia un sujeto (las futuras generaciones) que no es tangible en nuestro espacio temporal ${ }^{12}$. (ORTEGA \& ORTEGA, 2008, p. 499)

De acordo com os autores retro mencionados (ORTEGA \& ORTEGA, 2008, p. 499), a lei tem criado ficções jurídicas em diversas situações, por exemplo: as associações e sociedades, que adquirem nome, bens, representatividade, direitos e obrigações. A própria atividade estatal demonstra que uma entidade impalpável pode exercer atividades legais e se relacionar com outros Estados, organismos internacionais e Tribunais. Logo, seria irrelevante argumentar que as gerações vindouras são intangíveis.

El concepto de responsabilidad intergeneracional debe estar en el centro de cualquier tentativa de fundamentación de los derechos de generaciones futuras. Ahora bien, el análisis de este concepto nos revela uma serie de cuestiones que atañen a la reflexión propiamente filosófica. Uma de estas cuestiones concierne a nuestra capacidad para prever el futuro, otra concierne a la actitud ética que debemos asumir con base en nuestras previsiones. Una vez que estas cuestiones han sido resueltas, se está em condiciones de hablar de una extensión de la responsabilidad más allá del mero presente ${ }^{13}$. (ORTEGA \& ORTEGA, 2008, p. 501)

É possível a superação do formalismo jurídico clássico, a fim de evidenciar a obrigação das gerações contemporâneas para com aquelas que estão por vir. Os mecanismos jurídicos já existentes podem ser adequados para abarcar a proteção destes grupos não nascidos, mas que também merecem tutela estatal jurídica, para a preservação de seus interesses. Apegar-se ao

\footnotetext{
${ }^{12}$ Tradução livre: [Nosso ponto de partida é a seguinte constatação: Estados podem criar direitos e obrigações sob o princípio de pacta sunt servanda. Quando se tornou evidente que a responsabilidade para com as gerações futuras se repete em vários tratados internacionais, está-se em ondições de dizer que os estados-membros decidiram observar que seria um conduta de respeito face um sujeito (gerações futuras), que não é tangível em nosso espaço temporário].

${ }^{13}$ Tradução: [O conceito de responsabilidade entre gerações deve estar na centro de qualquer tentativa de justificar os direitos das gerações futuras. No entanto, a análise desse conceito revela uma série de questões relativas à reflexão propriamente filosófica. Uma dessas questões diz respeito à nossa capacidade de prever o futuro, outras preocupações a atitude ética que devemos assumir com base na nossa previsões. Uma vez que estas questões tenham sido resolvidas, está-se em condições de falar de uma extensão de responsabilidade para além do nosso presente].
}

Rev. de Direito e Sustentabilidade | e-ISSN: 2525-9687 | Porto Alegre | v. 4 | n. 2 | p. 1 -19 | Jul/Dez. 2018 
pragmatismo tradicional, atribuindo entraves a equidade intergeracional, apenas desvia o objetivo da teoria, que enseja a implementação de proteção às futuras gerações.

\subsection{Estratégias para Efetivação dos Direitos Intergeracionais}

Seria insuficiente apresentar a teoria da equidade intergeracional, sem apontar alguns mecanismos que estão sendo implementados com o fim de efetivar a proteção dos direitos intergeracionais. Deste modo, apresenta-se a seguir, alguns os principais caminhos apontados pelos pesquisadores, bem como alguns que já estão sendo colocados em prática com fins de garantir a proteção dos direitos intergeracionais.

Uma das opções apontadas pela Assembleia das Nações Unidas de 2013, refere-se à criação de um alto comissariado responsável por promover interações com os demais Estadosmembros, entidades e agências especializadas, oferecendo apoio e aconselhamento sobre a tomada de decisões e políticas públicas para fortalecer a solidariedade intergeracional. (UNITED NATIONS, 2013, p. 8/9). A criação deste escritório especializado recebeu forte apoio da sociedade civil.

Edith Brown Weiss afirma que a implementação dos direitos e obrigações intergeracionais devem ser adotados em dois níveis distintos, por meio de estratégias gerais e ações específicas. Para a autora, a estratégia mais contundente corresponde a representação das futuras gerações na tomada de decisões. Esta representação também far-se-ia por meio de um escritório especializado. A atuação de um alto comissariado que participasse da tomada de decisões administrativas, judiciais e inclusive de mercado, seria a principal estratégia a ser adotada.

This representation has to take place in several forms: in administrative decisionmaking, judicial decision-making, and most importantly, in the marketplace. For administrative and judicial decisions, one option is to appoint and publicly finance an office responsible for identifying and ensuring that interests of future generations are considered. This office could also be responsible for ensuring that laws regarding our environment and natural resources are observed, for investigating complaints, or for providing warnings of pending problems. The World Commission on Environment and Development recommended appointment of an ombudsman for future generations $^{14}$. (WEISS b, 1992, p. 25)

\footnotetext{
14 Tradução livre: [Esta representação tem de se realizar de várias formas: na tomada de decisão administrativa, na tomada de decisões judiciais e, mais importante, no mercado. Para as decisões administrativas e judiciais, uma opção é nomear e financiar publicamente um escritório responsável por identificar e garantir que os interesses das gerações futuras sejam considerados. Este escritório também poderia ser responsável por assegurar que as leis relativas ao nosso meio ambiente e recursos naturais sejam observadas, para investigar queixas ou para fornecer
} 
Alexandre Kiss destaca que, na França, o direito intergeracional já está institucionalizado. Em 1993 foi criado um Conselho de Gerações Futuras, estabelecido por meio de decreto. Este órgão atua como um consultor independente, que oferece aconselhamento, sempre que for identificado qualquer porblema com impacto potencial sobre os direitos das futuras gerações. (KISS b, 2004, p.21). Esta iniciativa demonstra, de forma prática, que é possível oferecer representatividade aos titulares dos direitos intergeracionais.

No Brasil, a proteção pelos direitos intergeracionais ainda é incipiente, não contando com nenhum conselho ou equivalente nacional para cuidar especificamente do tema. Sob o viés jurídico, a representação dos direitos intergeracionais no campo brasileiro ficaria a cargo do Ministério Público. O órgão, todavia, aloca uma dezena de responsabilidades, o que dificulta a sua dedicação a uma temática específica, tal como a proteção dos direitos das futuras gerações. A proteção ambiental ofertada pelo Ministério Público ainda é insuficiente para contemplar a magnitude da teoridade da equidade intergeracional.

Urge a necessidade de decentralizar a temática em terras nacionais, com a criação de comissões, órgãos consultivos, que possam atuar nas três esferas do poder público. A iniciativa privada e a população, também deve ser conclamada a participar e colaborar com criação de mecanismos e estratégias que sejam interligadas com as esferas de poder. Preconizar a garantia constitucional contida no art. 225, e não disciplinar a sua efetivação, acaba por conferir mero simbolismo ao direito intergeracional.

Entretanto, a história contemporânea ilustra a fragilidade de muitos Estados, alguns
dos quais são incapazes de impor sua autoridade sobre a população. Assegurar a
proteção dos direitos das futuras gerações supõe uma forma de continuidade que
somente pode ser alcançada com a participação de instituições internacionais. Além
disso, experiências com Estados totalitários demonstram também que o melhor
estímulo para alcançar a proteção dos direitos humanos é a existência de instituições
internacionais independentes, que podem avaliar sua efetiva implementação.
Assegurar os direitos das gerações futuras é uma tarefa muito mais difícil do que
assegurar o respeito pelos direitos humanos atuais. Isto deve ser outorgado a uma
autoridade internacional, talvez a um Alto Comissariado ou a uma Comissão Mundial,
como a Comissão Brundtland. (KISS b, 2004, p.21)

A comunidade científica nacional deve participar do debate e oferecer alternativas sob seus respectivos enfoques para apresentar alternativas. $\mathrm{O}$ estudo multidisciplinar entre direito, ética, filosofia faz-se extremamente necessário (ORTEGA \&ORTEGA, 2008, p.489). Além destes, outras áreas de conhecimento, tais como as ciências biológicas, as da saúde, as

avisos de problemas pendentes. A Comissão Mundial sobre Meio Ambiente e Desenvolvimento recomendou a nomeação de um ombudsman para futuras gerações]. 
econômicas e sociais devem gerir o tema e propiciar estudos interdisciplinares visando o aprimoramento da teoria, sob diversas perspectivas.

\section{CONSIDERAÇÕES FINAIS}

As gerações vindouras que foram destacadas neste estudo concentram-se em uma concepção racionalista, partindo da premissa de uma continuidade de reprodução da espécie humana, com o nascimento de novas pessoas de forma ininterrupta, o que aponta um elo sequencial na existência humana. Diversas pessoas nascem e morrem todos os dias, porém, a expectativa é de que a vida humana continue a existir de forma indeterminada ao longo do tempo, motivo pelo qual seria necessário assegurar a proteção daqueles que ainda estão por vir.

Partindo da premissa de que a vida humana continuará a existir nas próximas décadas ou séculos, é necessário romper o formalismo jurídico e identificar essas gerações como titulares de direitos, especificamente de direito ambientais, para que possam ter acesso a uma vida em condições ideias de sobrevivência e dignidade. A finitude dos bens ambientais demonstra a necessidade de equilibrar o uso do meio ambiente, sem esgarçar os recursos existentes, permitindo a conservação do acesso, da qualidade e das opções, as gerações vindouras, premissas básicas da teoria intergeracional.

Para assegurar a proteção ambiental intergeracional, variados mecanismos devem ser implementados para garantir a proteção dos direitos intergeracionais, podendo destacar-se, entre eles, a identificação de legitimados aptos a representar os interesses das populações vindouras. Tais legitimados atuariam de forma a intervir, sempre que fosse possível identificar lesões ambientais ao interesse das gerações vindouras. A criação de conselhos ou órgãos consultivos, também se apresenta como uma alternativa viável para a oferecer aconselhamento em decisões de cunho ambiental que possam comprometer o acesso aos recursos naturais para aqueles que estão por vir.

As ameaças ambientais e o esgotamento do meio ambiente não são exclusivos de um determinado território. Antes, pelo contrário, implica em afetação do meio ambiente como um todo, bastando tomar como exemplo as mudanças climáticas em andamento que provocam elevação de temperaturas, ocasiona derretimento de geleiras, e promove acréscimo no volume marítimo, avançando as águas marítimas sobre cidades e países inteiros à beira-mar.

A necessidade de uma governança ambiental em caráter global pode mudar a gestão do meio ambiente pelos Estados e agrupar esforços, que realizados em suas respectivas localidades, contribuirão de forma contundente para a proteção ambiental de forma difusa. A

Rev. de Direito e Sustentabilidade | e-ISSN: 2525-9687 | Porto Alegre | v. 4 | n. 2 | p. 1 - 19 | Jul/Dez. 2018 
partir desta premissa, é necessário observar que, deixar a governança apenas a cargos do plano internacional, não se mostra como alternativa coerente, pois as ações de governança ambiental também necessitam ser internalizadas em ações locais.

\section{REFERÊNCIAS}

BOLSON, Simone Hegele. A dimensão filosófico-jurídica da equidade intergeracional: reflexões sobre as obras de Hans Jonas e Edith Brown Weiss. In: Direitos Fundamentais \& Justiça - Ano 6, n. 19, Abr/Jun. 2012, p.210-236. Disponível em: <https://jus.com.br/artigos/24189/a-dimensao-filosofico-juridica-da-equidade intergeracional-reflexoes-sobre-as-obras-de-hans-jonas-e-edith brownweiss\#ixzz2Qq2aF5gz>. Acesso em: 21 mar. 2016.

BRANDÃO, Luiz Carlos Kopes; SOUZA, Carmo Antônio de. O princípio da equidade intergeracional. In: Planeta Amazônia: Revista Internacional de Direito Ambiental e Políticas Públicas. Macapá, n. 2, 2010, p. 163-175.

COSTA, Hirdan Katarina de Medeiros. O princípio da justiça intra e intergeracional como elemento na destinação das rendas de hidrocarbonetos: temática energética crítica na análise institucional brasileira. 2012. 342 f. Tese (Doutorado) São Paulo, 2012.

FIGUEIRA, Sérgio Sampaio. A função teleológica do princípio da equidade intergeracional no Direito Ambiental do Brasil. In: Planeta Amazônia: Revista Internacional de Direito Ambiental e Políticas Públicas. n. 2, Macapá, 2010, p. 01-10

KISS, Alexandre. Os Direitos e interesses das gerações futuras e o princípio da precaução. In: VARELLA, Marcelo Dias; PLATIAU, Ana Flávia Barros (Organizadores e coautores). Princípio da Precaução. Belo Horizonte: DelRey e ESMPU - Escola Superior do Ministério Público da União, 2004.

MENDES, Lara França. A justiça intergeracional: uma perspectiva do direito fundamental das futuras gerações ao meio ambiente. Dissertação (Mestrado). Universidade de Coimbra, 2016.

ORTEGA, Luiz Gabriel Ferrer; ORTEGA. Jesús Guillermo Ferrer. El problema de la fundamentación filosófica de los derechos de las generaciones futuras. In: Anuário Mexicano de Derecho Intrnacional, 2008. p.487-507. 8 v. Disponível em: <http://revistas.juridicas.unam.mx/index.php/derechointernacional/article/view/250>.

Acesso em: 11 out. 2016.

SILVA, Marcela Vitoriano E. O princípio da solidariedade intergeracional: um olhar do Direito para o futuro. In: Veredas do Direito, Belo Horizonte, v.8, n.16, Julho/Dezembro de 2011. p.115-146. 
UNITED Nations. General Assembly. Intergenerational solidarity and the needs of future generations. Report of the Secretary-General. Distr.: General. 5 August 2013 Original: English.

WEISS, Edith Brown. Intergenerational equity: a legal framework for global environmental change. Chapter 12 in Environmental change and international law: New challenges and dimensions, Edited by Edith Brown Weiss. Tokyo: United Nations $\begin{array}{llll}\text { University } & \text { Press, } & \text { 1992. } & \text { Disponível }\end{array}$ <http://www.unu.edu/unupress/unupbooks/uu25ee/uu25ee0y.htm\#12.\%20intergener ational\%20equity:\%20a\%20legal\%20framework\%20for\%20global\%20environmental $\% 20$ change>. Acesso em: 14 out. 2015.

WEISS, Edith Brown. In Fairness To Future Generations and Sustainable Development. American University International Law. Review 8, n. 1, 1992. p. 19-26. 